\title{
Juan Luis Sariego y el oficio de antropólogo*
}

\author{
LUIS REYGADAS
}

Juan Luis Sariego and the Craft of Anthropology

LUIS REYGADAS Universidad Autónoma MetropolitanaIztapalapa, Distrito Federal, México reygadasl@gmail.com

Desacatos 50, enero-abril 2016, pp. 186-199 onocí a Juan Luis Sariego un domingo de junio de 1979, en la ciudad de México. Al día siguiente él viajaría a Cananea, Sonora, para realizar trabajo de campo sobre la minería del cobre. En aquella época, Juan Luis tenía casi 30 años de edad, estaba haciendo su tesis de maestría y ya era investigador del Centro de Investigaciones Superiores del Instituto Nacional de Antropología e Historia (CISINAH), hoy Centro de Investigaciones y Estudios Superiores en Antropología Social (CIESAS). Yo apenas había terminado los cursos de la licenciatura en antropología en la Escuela Nacional de Antropología e Historia (ENAH). Quería hacer mi tesis sobre los trabajadores mineros y metalúrgicos, quienes aparecían ante mis ojos como la vanguardia de las luchas obreras y sociales en el país. Mi proyecto de investigación tenía el pretencioso título "Las luchas de los trabajadores minero-metalúrgicos en México, 1968-1978”. Albergaba la ingenua intención de hacer trabajo de campo en varias zonas mineras y metalúrgicas.

Desde el punto de vista académico y antropológico, la investigación que tenía en mente no era muy sólida. Correspondía más a los ideales de un militante que había leído mucho El capital, de Marx, había discutido con intensidad los procesos de trabajo en talleres de investigación en la ENAH y quería ir al encuentro de la clase obrera. Tenía montones de preguntas y mucho entusiasmo, pero sabía poco sobre cómo hacer una investigación. Por suerte, un amigo de la preparatoria conocía a Juan Luis y me contó que había hecho trabajo de investigación en zonas mineras. Le llamé por teléfono a media semana y me dijo que el lunes siguiente se iría a Cananea, donde estaría dos meses. Otro me hubiera respondido que esperara a su regreso para concertar una cita en su oficina, pero Juan Luis era generoso. Me propuso ir el domingo a desayunar a su casa para hablar.

Las fotografías para esta colaboración fueron proporcionadas por Lorelei Servín de Sariego, a quien agradecemos su generosidad. 
En ese tiempo, Patricia Cabrera y Juan Luis Sariego vivían en Tlalpan, en una casita del callejón de Ximilpa. Llegué y me encontré con un español afable, sonriente, con bigote, que empezaba a quedarse calvo. No recuerdo qué desayunamos, pero tomamos un buen café expreso. El "cafelito" siempre fue parte de la vida cotidiana de Juan, preparado en la clásica cafetera italiana. Conversamos los tres durante varias horas. Más bien, Patricia y yo intercalamos algunos silencios y comentarios en medio del mar de palabras que brotaba de los labios de Juan Luis. Le conté lo que quería hacer para mi tesis. Al principio me pareció que no me había escuchado, porque continuó hablando y hablando. Tuve esta misma sensación en muchas ocasiones posteriores. Después entendí que el hecho de hablar mucho no le impedía a Juan Luis escuchar y comprender bien a sus interlocutores.

Me explicó que en el CIS-INAH ya llevaban un tiempo trabajando sobre el tema de la minería, que tenían un proyecto de investigación llamado "Los mineros mexicanos" con el que habían recorrido varias zonas mineras del país, en especial en Zacatecas, Coahuila, Chihuahua y Sonora. Habían decidido concentrarse en dos regiones: la de producción de cobre en Cananea y Nacozari, Sonora, y la zona carbonífera del norte de Coahuila. A la mañana siguiente saldrían hacia Cananea, de donde regresarían en agosto. Estarían un mes en la ciudad de México y partirían hacia la cuenca carbonífera de Coahuila. Esta región me interesaba de manera especial, porque hacía poco tiempo había leído el libro La caravana del hambre, de Daniel Molina (1978), que narra en un estilo vibrante la lucha de los mineros de Nueva Rosita y Cloete, quienes después de una larga huelga, emprendieron en 1951 una heroica marcha hasta la ciudad de México para protestar contra la imposición gubernamental de dirigentes en el Sindicato de Trabajadores Mineros y Metalúrgicos de la República Mexicana (STMymRM). Entonces se produjo una segunda muestra de generosidad por parte de Juan Luis: me propuso integrarme al equipo que saldría en septiembre hacia Nueva Rosita, para realizar dos meses de trabajo de campo con los mineros de carbón. Tenía unas horas de conocerme, no sabía gran cosa sobre mí y de buenas a primeras me invitaba a unirme al trabajo de campo que iba a realizar con su equipo de investigación. Más tarde entendí que en esa propuesta había algo más que generosidad: le encantaba el trabajo de campo y quería que todos los antropólogos trabajaran sobre el terreno durante el mayor tiempo posible. De inmediato acepté incorporarme a la expedición.

Desde ese primer encuentro han pasado más de 35 años. Apenas ahora soy consciente de que en aquella ocasión Juan Luis no trató de "enseñarme" cómo hacer mi tesis, no me brindó consejos ni me dio lecciones sobre minería, algo que pudo haber hecho sin dificultad porque había leído mucho sobre el tema, tenía experiencia de investigación y ya había publicado un pequeño libro sobre los mineros de Real del Monte (Sariego, 1978). En lugar de eso, me invitó a participar en un proceso de investigación, a incorporarme a un proyecto antropológico en marcha. Fue una propuesta que sugería una relación igualitaria, pese a las diferencias de edad, experiencia y conocimientos. Con los años me di cuenta de que la horizontalidad era un aspecto central de la antropología para Juan Luis. Aunque tenía cualidades de líder y muchos conocimientos, no se ponía a pontificar, lo que hacía era discutir y compartir lo que sabía. Creía que la antropología no era una suma de conceptos o un conjunto de técnicas que podían enseñarse en el aula, sino un oficio que buscaba comprender la diversidad cultural, que se tenía que aprender en la práctica, en una investigación concreta.

En aquellos años, mi relación con la antropología estaba muy influida por la participación política. No tenía experiencia de investigación académica, pero durante varios años había vivido y hecho trabajo político en un pueblo y en un barrio 
popular al sur de la ciudad de México, con el objetivo de promover la formación de organizaciones populares. En esa zona había hecho mucha "observación militante”, que incluyó realización de diarios de campo, entrevistas, encuestas, información hemerográfica, participación en reuniones y movilizaciones, intensas discusiones y otras actividades ligadas a la dinámica cotidiana de la movilización social. Todo esto aportó aprendizajes que después me servirían en el mundo académico, pero hasta aquel momento mi interés en la antropología era muy limitado. Consideraba a la antropología una “disciplina burguesa”, a mí me interesaba el marxismo. Aunque había terminado los cursos de la ENAH, los textos de antropología que había leído se podían contar con los dedos de las manos. No sabía que el trabajo de campo en Nueva Rosita trastocaría por completo mi vínculo con la disciplina.

\section{El diálogo entre la observación y la teoría}

El equipo del CIS-INAH salió de la ciudad de México hacia Nueva Rosita a mediados de septiembre de 1979. Además de Juan Luis Sariego, iban los otros cuatro integrantes del proyecto sobre minería: el ecuatoriano José Díaz Estrella, el peruano Raúl Santana y dos mexicanos, Daniel González y Federico Besserer, que eran más o menos de mi edad y que también hacían su tesis de licenciatura. Se unió otra integrante del área de industrialización y clase obrera del CIS-INAH, Victoria Novelo, quien para ese entonces ya tenía una sólida trayectoria de investigación sobre antropología del trabajo. Rentaron una Combi blanca, que los siguientes dos meses estaría renegrida por el polvo de carbón. Yo no viajé con ellos, los alcancé unos días más tarde.

Después de un viaje de autobús que duró más de 15 horas, llegué a la zona carbonífera el 20 de septiembre de 1979. En Nueva Rosita, el grupo del CISINAH rentó dos casas, una con varias habitaciones y otra más pequeña para Juan Luis y Patricia Cabrera, quien nos alcanzaría unos días después para incorporarse al equipo. En lo que llegaba Patricia, me quedé unos días en la casa pequeña con Juan Luis, a la que llegábamos a dormir después de haber estado todo el día haciendo trabajo de investigación o en reuniones con el resto del grupo en la otra casa. Desde esas primeras noches en Nueva Rosita se produjo un fenómeno que se repitió a lo largo de muchos años: Juan Luis podía hablar durante horas enteras y a mí me gustaba oírlo. Cada noche pasábamos largos ratos en la oscuridad, fumando y conversando. Ahí nació una gran amistad y un diálogo intelectual en el que aprendí a pasos acelerados, escuchando todo lo que él me contaba sobre la minería y la antropología.

Los dos meses que pasamos en Nueva Rosita fueron la experiencia más rica de toda mi formación como antropólogo. Comenzamos con la observación de las minas y plantas de beneficio. La primera mina a la que me tocó bajar fue la 2 de Barroterán, en la que 10 años antes se había producido la explosión que causara la muerte de 153 mineros. Conocer esas ciudades subterráneas y ver cómo trabajaban los mineros en medio de nubes de polvo negro es algo que deja huella. Bajamos a varias minas y pocitos en Nueva Rosita, Palaú, Cloete, Barroterán, La Florida y Esperanzas, además de recorrer hornos de coque y la planta de beneficio de Nueva Rosita. Fue un privilegio hacerlo con todo el grupo, en especial con Juan Luis y Victoria, ${ }^{1}$ quienes veían cosas que los demás no advertíamos. Juan Luis le daba

Aunque participaron en las demás actividades, Victoria Novelo y Patricia Cabrera no pudieron bajar a las minas, debido a que en esa época las empresas no autorizaban que entraran mujeres, argumentando razones de seguridad. Algunos mineros decían que la mina era mujer y como hurgaban en sus entrañas, la mina se "encelaba" si bajaba una mujer, lo que podía provocar accidentes. Pocos años después desaparecieron esos tabúes y prohibiciones y algunas mujeres comenzaron a trabajar en las minas de carbón de Coahuila, incluso ingenieras mineras. 
gran importancia a la observación, tenía la escuela de Ángel Palerm. Relataba que en los recorridos de campo, Palerm llevaba a los alumnos a un punto alto para comenzar a entender el panorama de una región. También tenía la escuela de su padre, Juan Luis recordaba que era un gran observador:

Yo creo que a él lo hizo observador su origen rural y la Guerra Civil. Nos hizo muy observadores de la naturaleza. Íbamos por la carretera y “aquí, detrás de esta curva, ¿qué árbol hay?” y “¿cómo se llama ese cerro?”. Muy observador. Yo creo que la antropología, una de sus funciones básicas, de sus métodos básicos, es la observación. Y yo me he dado cuenta que yo, como muchos antropólogos, nos volvemos obsesivos, todo observamos, incluso cuando no ejercemos. Va uno en un autobús y dice: "esos dos han de ser una pareja informal y esos dos son separados" [...]. Yo a mis alumnos, cuando los llevo al campo, la primera fase, una semana, cuatro o cinco días, les digo: "A ver, vayan a recorrer la sierra, una zona". Les digo: "Prohibido preguntar, observen. Saluden y eso, pero no pregunten, observen". ${ }^{2}$

Para Sariego no se trataba de observar por observar. Esta práctica era parte de un esfuerzo de comprensión, en el que se ponían a dialogar la información empírica y la teoría. Ponía el ejemplo de Palerm, que al observar desde lo alto las terrazas de cultivo comenzaba a hablar del modo de producción asiático. Cuando caminábamos por las calles de Nueva Rosita o de Esperanzas, Juan Luis trataba de averiguar si se aplicaban las tesis de las teorías del enclave y los company towns, según las cuales la dinámica urbana giraba en torno a las necesidades de una rama industrial, de manera que los actores principales de dicha industria — empresa y trabajadores - se constituían también como protagonistas de la vida de la ciudad (Zapata, 1977). De esta manera indagaba cómo la configuración espacial de Nueva Rosita correspondía a la división del trabajo en la empresa minero-metalúrgica: barrios en los que predominaban los directivos de la empresa, barrios en los que mayoría de los habitantes eran empleados de confianza y barrios obreros. Asimismo, advertía que la empresa Industrial Minera México era la principal proveedora de muchos servicios urbanos y sociales: escuelas, hospitales, transporte, pavimentación, etc. También estaba atento a la transformación de ese modelo, en la medida en que la presencia del sindicato minero y de diferentes agencias estatales - Instituto Mexicano del Seguro Social, Secretaría de Educación Pública, municipio, gobierno del estado, dependencias federales - iban adquiriendo mayor relevancia, observación que le permitió construir el disonante concepto de "desenclavización", que aludía al proceso de diversificación económica, política, social y cultural que experimentaron los centros mineros después de la formación del sindicato en la década de 1930, y sobre todo, después de la promulgación en 1961 de la llamada ley de “mexicanización” de la minería, que hizo posible la mayor intervención del Estado en el sector. Para Sariego, la teoría y la observación en el campo eran tareas complementarias.

\section{Entrevista antropológica y clase obrera realmente existente}

Además de la observación, en ese trabajo de campo pude aprender el arte de la entrevista antropológica. El equipo había preparado guías para realizar entrevistas a profundidad con trabajadores, supervisores, ingenieros mineros, gerentes, líderes

\footnotetext{
2

"Juan Luis Sariego, investigador emérito del INAH", disponible en línea: <https://www.youtube.com/watch?v=MTpE_ CLM2qk>. Consultado el 24 de marzo de 2015. Video basado en la entrevista que realizó Arturo Herrera a Juan Luis Sariego en 2014.
} 


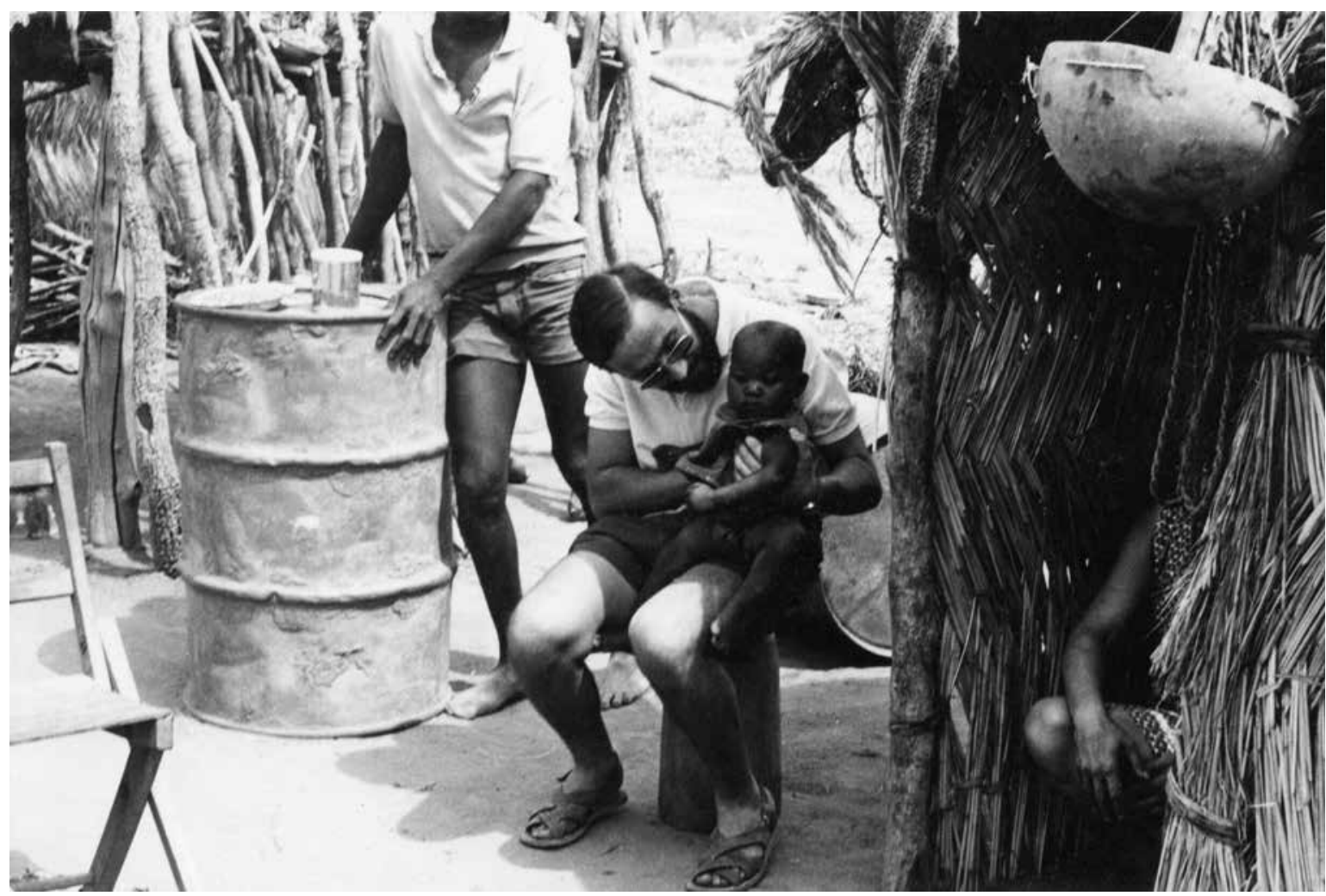

- Juan Luis Sariego a los 22 años de edad, como novicio de la Compañía de Jesús, acoge en sus brazos a un niño nár. Bekamba, Chad, 1971.

sindicales, autoridades locales y otros actores. Las entrevistas con los "caravaneros" - ex mineros que habían participado en la huelga y la caravana del hambre en 1950-1951 - fueron conmovedoras y nos permitieron introducirnos en las complejidades de la recuperación de la memoria histórica. En aquellos años, entre los historiadores comenzaba a ponerse de moda la historia oral, pero Juan Luis comentaba que eso no era ninguna novedad, que desde tiempo antes la antropología hacía historia oral. Las conversaciones con viejos mineros que habían fundado las organizaciones gremiales y sindicales en la región carbonífera también fueron de una riqueza increíble. Hicimos muchas entrevistas para tratar de comprender los procesos de trabajo en la minería del carbón. La mayor parte del equipo estaba interesada en temas relativos al trabajo, el sindicalismo y la cultura obrera. A Juan Luis también le apasionaban esos temas, pero insistía en no desligar el trabajo de otros aspectos de la vida urbana y comunitaria, por lo que promovía que entrevistáramos a maestros de escuela, médicos y autoridades locales.

Ante el sesgo "obrerista" que teníamos muchos, Juan Luis proponía que también habláramos con los técnicos y los directivos de las compañías mineras. Ahí aprendí un principio básico de la antropología: hay que saber escuchar a todos, es necesario ponerse en los zapatos de distintos sujetos. Al principio sólo me interesaban los mineros combativos, que luchaban contra las burocracias sindicales y las empresas, pero en Nueva Rosita entendí que podía aprender mucho al conversar con todo tipo de trabajadores, con dirigentes sindicales de todas las tendencias políticas —incluidos aquellos que identificábamos 
como charros-, con supervisores, técnicos, ingenieros mineros y directores de las empresas. Nunca imaginé que para entender el proceso de formación de las organizaciones obreras de la cuenca carbonífera era clave hablar con los dirigentes de las logias masónicas, que habían tenido un papel relevante en la construcción de liderazgos en la región. También descubrí que las cantinas eran un espacio crucial para la formación de grupos y corrientes sindicales y que en ellas se tomaban muchas de las decisiones que después se aprobaban en las asambleas de las secciones sindicales.

Para esta apertura de la escucha influyó mucho Juan Luis, porque era buen conversador. Sabía entrevistar a todo tipo de personas, sin aires de superioridad frente a un trabajador de base y sin amilanarse frente a un dirigente nacional del sindicato minero o un alto directivo de una compañía minera. Lograba que las entrevistas fluyeran porque conseguía crear un ambiente de confianza, mediante el establecimiento de una relación horizontal y respetuosa con cualquier entrevistado. Esto no era una cuestión técnica, sino algo más profundo, una convicción sobre la valía del otro, sobre la posibilidad y la necesidad del diálogo intercultural. Como cualquier interacción social, la entrevista antropológica está atravesada por relaciones de poder entre los sujetos que intervienen en ella. Muchas veces se establecen relaciones de tipo colonial, en las que el antropólogo, occidental y de clase media, "extrae" información de los otros. Con Juan Luis y con el resto del equipo aprendí que existían diversos modelos de entrevista, algunos más respetuosos y dialógicos, con relaciones más abiertas, en los que el antropólogo busca aprender y comprender, en los que se trata de escuchar al otro y de valorar lo que la otra persona quiere decir. En mi trabajo político previo había conversado mucho con habitantes de colonias populares de la ciudad de México y trataba de "escuchar a las masas". Con la clara intención de detonar una transformación revolucionaria, la escucha estaba supeditada a un proyecto político y a la intención, no exenta de colonialismo, de fomentar la conciencia de clase de acuerdo con un modelo ideal de lo que debía ser el proletariado. En la región carbonífera aprendí a mirar a los mineros realmente existentes. Unos años después, en 1984, esta aproximación a la clase obrera de carne y hueso fue bellamente plasmada por tres miembros del equipo, Victoria Novelo, Federico Besserer y Daniel González, quienes con otros colegas montaron la exposición "Obreros somos, expresiones de la cultura obrera", en el Museo de Culturas Populares.

Otro aprendizaje de aquella época fue el trabajo en equipo. Aunque cada integrante del grupo tenía diferentes intereses de investigación, todos hacíamos entrevistas sobre todos los temas y la información era patrimonio común. A Juan Luis le gustaba hacer investigación en equipo. Decía que eso también lo había aprendido con Ángel Palerm:

Yo creo que Ángel Palerm nos enseñó mucho acerca de cómo llevar a cabo un trabajo de investigación. Por ejemplo, yo aprendí con él virtudes del trabajo en equipo, modelo que era característico del CIS-INAH y que permitía la titulación de estudiantes y la publicación de muchos textos. También supe cómo el trabajo de campo se articula con los seminarios de investigación (entrevista con Juan Luis Sariego, realizada por Luis Felipe Castro Oviedo, 24 de febrero de 2006).

El trabajo de ocho antropólogos dedicados a realizar entrevistas en profundidad durante dos meses y a transcribirlas durante los meses posteriores arrojó un corpus de información muy vasto. Recuerdo como un tesoro las carpetas de colores en las que reunimos las decenas de entrevistas transcritas, que cubrían varios temas y actores muy diversos. La información contenida en ellas fue tan rica que constituyó el material fundamental para la elaboración de varios libros, capítulos de libros, artículos y 
tesis, incluyendo la de maestría de Juan Luis, "Enclaves y minerales en el norte de México. Historia social de los mineros de Cananea y Nueva Rosita, 1900-1970", presentada en 1985 en la Universidad Iberoamericana, por la que obtuvo el Premio Fray Bernardino de Sahagún a la mejor tesis de maestría en antropología social en 1986.

\section{Trabajo de archivo. Antropología e historia}

Otro de los grandes descubrimientos del periodo de campo en la zona carbonífera fue el trabajo de archivo y la investigación histórica. Como militante impaciente, me interesaba mucho más el presente y sobre todo el futuro. Nunca había investigado en archivos y por iniciativa propia no hubiera emprendido esa actividad. Imaginaba que la revolución estaba a la vuelta de la esquina y no había tiempo que perder al mirar hacia atrás. A Victoria Novelo le interesaba sobremanera la historia de los caravaneros y Juan Luis Sariego se inclinaba fuertemente por la perspectiva histórica y procesual. A partir de este enfoque, la revisión de archivos se convirtió en una de las tareas centrales de nuestro trabajo en la región carbonífera. Además de las minas de carbón, encontramos varias minas de oro: archivos de las empresas mineras, archivos sindicales, archivos de los participantes en la huelga y la caravana del hambre de 1950-1951 y archivos personales de viejos mineros. Con ellos pudimos documentar la evolución de las empresas, la transformación de los sistemas de organización del trabajo en la explotación del carbón, el devenir de las comunidades mineras, los antecedentes de las organizaciones sindicales, la historia del sindicato minero en la región, los detalles de los conflictos obrero-patronales, las huelgas y las negociaciones de los contratos colectivos, así como la cotidianidad del trabajo minero y de la resistencia obrera. Este trabajo de archivo me resultó tan fascinante, que el tema central de mi tesis de licenciatura fue la historia de la relación entre los procesos de trabajo y las acciones obreras en las minas de carbón en Nueva Rosita (Reygadas, 1983). ${ }^{3}$ Utilicé el material que habíamos recabado mediante observación y entrevistas, en especial la información que obtuvimos en los archivos de Industrial Minera México y de la Sección 14 del sindicato minero. Sin darme cuenta, en ese periodo de trabajo de campo y en los años posteriores de análisis de la información, abandoné el proyecto original de mi tesis, que abarcaba las luchas recientes en varias empresas minero-metalúrgicas en diversas regiones del país, para realizar una historia antropológica de los trabajadores de una sola población.

No se trató de utilizar una técnica que no había empleado antes — la revisión de archivos- o de hacer una investigación más acotada —estudiar una empresa en lugar de varias- Lo realmente importante es que mediante la perspectiva histórica que Juan Luis nos proponía se produjo un cambio significativo en mi manera de ver a los trabajadores mineros, al insertarlos en contextos específicos, situados en el tiempo y el espacio. Juan Luis decía que esto era algo que también le había imbuido Palerm:

¿Cuáles son sus aportaciones? Creo que todos los que estudiamos con él [Ángel Palerm] quedamos muy influidos por su enfoque. Por ejemplo, uno muy importante, que yo creo que hoy es un tema muy polémico en la antropología mexicana, es lo que podemos llamar la relación de la antropología con el campo de la historia. Palerm siempre insistió en que el tema central de la antropología era la evolución, el cambio social, la dinámica social [...]. Digamos que nosotros no teníamos muchos referentes, usábamos básicamente a un autor, que precisamente fue Palerm quien nos incitó a leerlo y que le encontramos una enorme potencialidad para entender lo

3 De esta tesis derivó el libro Proceso de trabajo y acción obrera. Historia sindical de los mineros de Nueva Rosita, 1929-1979 (Reygadas, 1988). 
que estaba pasando en México. Es Edward P. Thompson con su famoso libro aquél sobre la formación de la clase obrera en Inglaterra, ${ }^{4}$ que todavía lo leíamos en inglés en aquella época. Lo que aporta ese texto son muchas cosas, pero una de ellas es la de superar esa visión mecánica con que se había visto la formación de las clases obreras en muchos países. Como dice Thompson en la introducción: hay que superar esa visión mecanicista según la cual "clase obrera = energía del vapor + proletarización campesina". Por el contrario, hay que pensar que la clase obrera es el resultado de un proceso histórico complejo, heterogéneo, específico en cada país, con idas y a veces con regresos, que significó, antes que nada, la toma de conciencia de artesanos y campesinos desposeídos de que ellos constituían una clase con intereses distintos de los que detentaban los empresarios y el Estado. De ahí surgió en nosotros la necesidad de estudiar cómo se dio este proceso en diferentes ramas industriales, regiones y periodos históricos de México (entrevista con Juan Luis Sariego, realizada por Luis Felipe Castro Oviedo, 24 de febrero de 2006).

Quizá ningún autor haya contribuido tanto a la comprensión de la clase obrera realmente existente como Edward P. Thompson, quien había escrito en el "Prefacio" de su obra más famosa:

Hoy día existe la tentación, siempre presente, de suponer que la clase es una cosa. No fue tal el sentido que le dio Marx en sus propios escritos de tipo histórico, aunque el error vicia muchos de los recientes escritos "marxistas". Se supone que "ella", la clase obrera, tiene una existencia real, que se puede definir de una forma casi matemática: tantos hombres que se encuentran en una determinada relación con los medios de producción. Una vez asumido esto, es posible deducir qué conciencia de clase debería tener "ella" (pero que raras veces tiene) si fuese debidamente consciente de su propia posición y de sus intereses reales. Hay una superestructura cultural a través de la cual este reconocimiento empieza a evolucionar de maneras ineficaces. Estos "atrasos" culturales y esas distorsiones son un fastidio, de modo que es fácil pasar desde ésta a alguna teoría de la sustitución: el partido, la secta o el teórico que desvela la conciencia de clase no tal como es, sino como debería ser (Thompson, 1977: XIV).

Creo que una de las grandes aportaciones del programa sobre industrialización y clase obrera del CISINAH, encabezado por Victoria Novelo y Juan Luis Sariego a finales de la década de 1970 y principios de la de 1980, fue abrir en México un programa de investigación sobre la historia, la cultura, el trabajo, la vida cotidiana y las luchas de los trabajadores realmente existentes, que rompió con las visiones acartonadas que prevalecían en aquel tiempo, centradas en el estudio de los sindicatos a partir de fuentes hemerográficas.

\section{La combinación de técnicas cuantitativas y cualitativas}

La antropología no sólo es una disciplina científica y humanística, es también un oficio que se aprende en la práctica. Casi siempre se aprende de manera solitaria, haciendo trabajo de campo en una región remota y tomando decisiones metodológicas sobre

\footnotetext{
$4 \quad$ Se refiere a Thompson (1977). Victoria Novelo recuerda que fue John Womack quien la introdujo en la lectura de Thompson y que a partir de ese momento circularon los trabajos de este autor entre los integrantes del área de industrialización y clase obrera del CIS-INAH. Independientemente de quién haya sido el introductor de los textos de Thompson, lo relevante es que ese grupo de antropólogos fue un lector temprano de su obra y recuperó su enfoque en diversas investigaciones en México.
} 


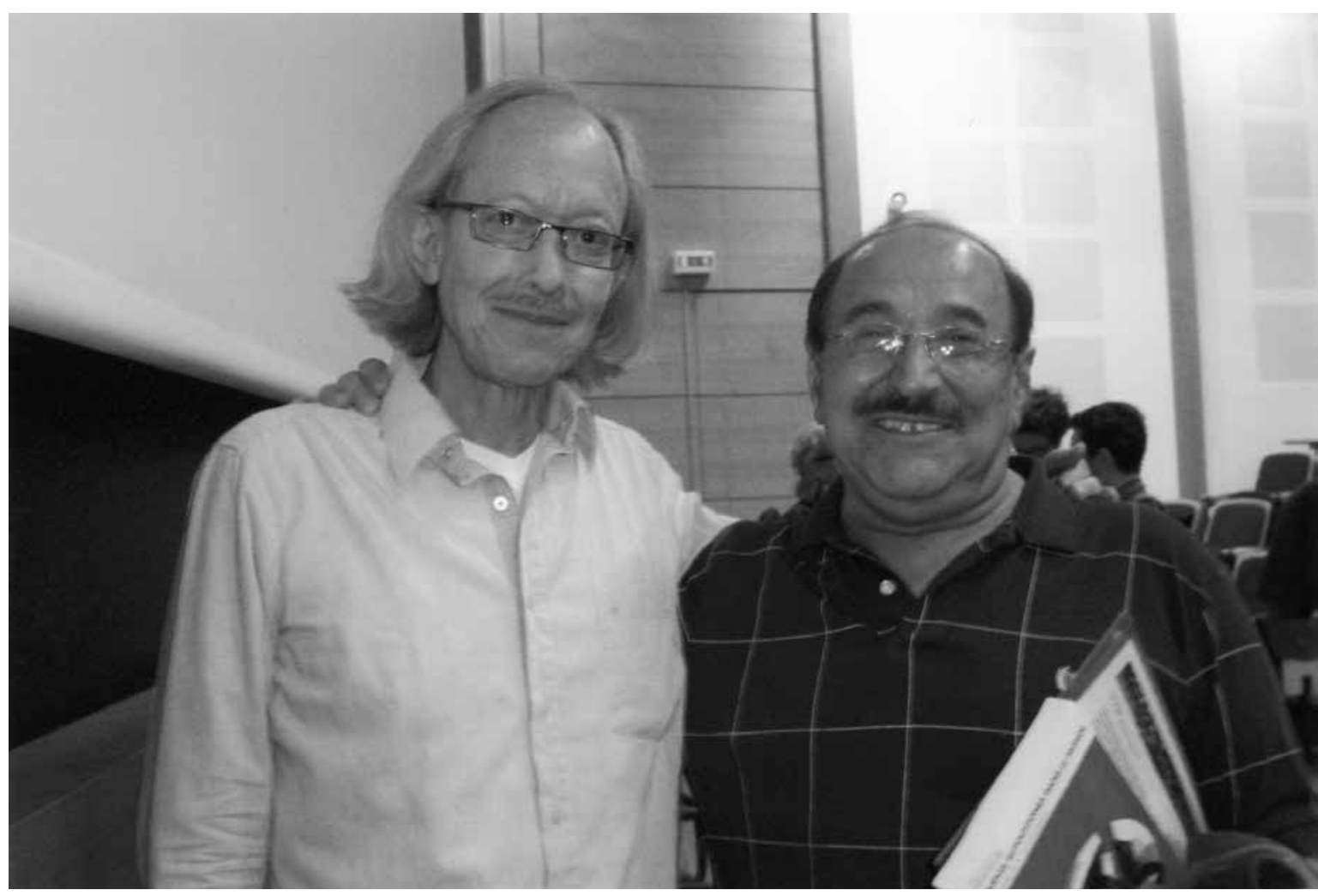

- Arturo Escobar y Juan Luis Sariego en el Simposio Interamericano de Investigación de la Educación, organizado por la Universidad de California Los Ángeles. Estados Unidos, 2013.

la marcha. La experiencia del contacto prolongado con la alteridad es ineludible, hay que vivirla en carne propia. Al igual que los jóvenes aprendices en los antiguos gremios artesanales, el aprendiz de antropólogo puede avanzar mucho si observa cómo trabajan los maestros del oficio y cómo resuelven los dilemas que se presentan en el trabajo de campo. Durante esos dos meses en Nueva Rosita durante el otoño de 1979, solíamos reunirnos los ocho, antes o después de la cena, para evaluar el trabajo realizado y planear las siguientes actividades. Algunas de las discusiones más intensas tuvieron que ver con la realización de una encuesta a trabajadores mineros. Muchos desconfiaban de un instrumento de esa naturaleza, dada la preferencia de la mayoría de los antropólogos por las técnicas llamadas cualitativas.
Las visitas a las minas, la observación del proceso de trabajo, los recorridos de área, la revisión de archivos y las entrevistas nos estaban proporcionando tanta información que no era claro qué elementos adicionales aportaría una encuesta. Además, muchos no sabíamos hacer una encuesta. Mis conocimientos de estadística eran nulos. Juan Luis fue el principal defensor de la aplicación del cuestionario a una muestra aleatoria de trabajadores. No veía una oposición radical entre métodos cuantitativos y cualitativos. Decía algo así como: "con las técnicas cuantitativas siempre se busca medir alguna cualidad y las cualidades no son ajenas a las cantidades". Poco a poco y no sin debate, nos fue convenciendo de la importancia de realizar una encuesta. Al final, decidimos hacer una muestra aleatoria de 
10\% de los trabajadores de base de varias empresas de la zona. Eso nos dio acceso a una información invaluable: los listados de personal de las principales compañías mineras de la región, con las que pudimos bosquejar la configuración de la fuerza de trabajo en términos de puestos, edad, antigüedad, etc. El diseño del cuestionario implicó numerosas discusiones, hasta que logramos encontrar las formulaciones más adecuadas. Con ello comprendí las sutilezas y los matices que se esconden en los tipos de preguntas y en las maneras de formularlas, arte en el que Juan Luis y otros integrantes del equipo eran muy diestros. Él tenía claro los tipos de muestra que podían utilizarse y las posibilidades de análisis. Yo no sabía nada de esta cuestión, más allá de totales y porcentajes, pero con esa encuesta descubrí lo que eran las ponderaciones, la Xi cuadrada y los coeficientes de correlación. La aplicación de la encuesta nos abrió muchas puertas: trabajadores, dirigentes sindicales y empresas comenzaron a tomarnos más en serio, en particular cuando nos vieron aplicar los cuestionarios en la noche y en la madrugada, pues decidimos cubrir los tres turnos de trabajo. A partir de la encuesta, surgieron innumerables contactos para hacer otras entrevistas y pudimos plantear nuevas preguntas de investigación. Gracias a ese trabajo de campo y a la terquedad de Juan Luis para aplicar la encuesta, entendí los alcances y las limitaciones de las técnicas cuantitativas y descubrí la potencia de la combinación de diversas aproximaciones metodológicas.

\section{El autodidacta y el aprendizaje del oficio}

Después de regresar de la región carbonífera, Juan Luis me apoyó para que siguiera en el equipo de investigación del CIS-INAH como prestador de servicio social, lo que me dio la oportunidad de aprender en la práctica una de las fases más importantes de la investigación: la sistematización y el análisis de la información. Se requirió hacer mucha talacha y no hubo distinciones: todos participamos en todas las tareas, incluso los más experimentados, Juan Luis el primero de ellos. En ese contexto, lo más natural fue pedirle a Sariego que fuera mi director de tesis, propuesta que aceptó de buen grado. Curiosamente, durante varios años no tuvimos una sola reunión para comentar los avances de mi tesis. Nos reunimos en una ocasión, a finales de 1982, cuando concluí la redacción del primer borrador, para que me hiciera comentarios y sugerencias muy útiles para mejorar la versión final. No le pedí asesoría previa, habían sido más que suficientes las numerosas reuniones de trabajo que habíamos tenido con todo el equipo de investigación. Juan Luis tampoco me pidió u ofreció ninguna reunión para supervisar mi trabajo. Eso se explica porque él fue autodidacta, aprendió el oficio de antropólogo en solitario, cuando estuvo en África entre 1971 y 1973:

Es más, si quieres que te diga la verdad, muchas cosas que luego aprendí en los libros ya las había empezado a aprender en esa práctica autodidacta allá en África. Yo estuve viviendo durante algo más de dos años, dos años y medio, en un país en el centro de África, la República de Chad, un país situado en la franja subsahariana, aunque cerca de dos terceras partes de su territorio se encuentran en ese desierto. Lo que yo hice ahí fue, en cierta forma, lo que luego leí que Malinowski recomienda a los antropólogos: adentrarse en otra cultura a través del aprendizaje de la lengua y un trabajo de campo sistemático. Recuerdo haber leído después la introducción de Malinowski y decir "pues eso es lo que yo hice" (entrevista con Juan Luis Sariego, realizada por Luis Felipe Castro Oviedo, 24 de febrero de 2006).

Tal vez su aprendizaje autodidacta de la antropología había comenzado antes, en España, cuando fue seminarista jesuita. Como parte de su formación, 
tuvo que llevar a cabo las denominadas "experiencias sociales", en las que los novicios tienen que ganarse el sustento mediante trabajos, por lo general manuales. En su caso, en el verano de 1967 —a los 17 años de edad- trabajó como peón albañil en una empresa de Ponferrada, León, y durante el verano de 1968 fue asistente-enfermero en un asilo de ancianos y enfermos crónicos en Toro, Zamora. Pasar la jornada trabajando al lado de obreros de la construcción o de ancianos y enfermos era una experiencia de contacto con la alteridad, pero nada comparado con los dos años que pasó en Chad, en una comunidad nar en la que él era el único europeo.

En esa época, el superior de los jesuitas en Chad era Charles Vandame, lingüista y sacerdote francés. ${ }^{5}$ Para fortuna de la antropología, prohibió a Juan Luis Sariego hacer cualquier tipo de trabajo de convencimiento religioso y le señaló que su principal tarea sería convivir con los nar y aprender su lengua, para redactar un método con la finalidad de que los próximos misioneros aprendieran con mayor facilidad el nar. Unos años antes, en 1968, el propio Vandame había escrito una gramática del kenga, otra lengua nilosahariana que se habla en Chad. Juan Luis cumplió con el encargo y escribió el que fue su primer libro: Recueil de textes nar (Tchad) (Sariego, 1973).

No debió ser fácil para Sariego sumergirse en un mundo por completo distinto al que conocía hasta entonces. Muchas veces me contó sobre el desconcierto que experimentó durante los primeros meses, cuando no entendía nada, ni del idioma ni de la cultura. ¿Qué habrá sentido cuando, en África, contrajo el paludismo y lo atacaban en las noches y en las madrugadas las intensas fiebres características de esa enfermedad? Lo que sabemos es que la experiencia lo templó y nació entonces su pasión por el trabajo de campo antropológico. Regresó a España a tomar cursos de antropología en la Universidad Complutense de Madrid (1973-1974), pero tuvo que seguir aprendiendo la antropología por su cuenta, debido a las circunstancias políticas de los últimos años del franquismo:

Para evitar las manifestaciones y asambleas, lo que hacía el gobierno franquista en esa época era clausurar temporalmente las facultades y escuelas. Se suspendían por meses las clases y nos daban un programa con el que preparábamos el examen final al que nos presentábamos "por libre”. ¡Así que no nos quedó de otra que volvernos autodidactas! (Entrevista con Juan Luis Sariego, realizada por Luis Felipe Castro Oviedo, 24 de febrero de 2006).

\section{Trabajo de campo y horizontalidad}

En virtud de que no encontró en España un ambiente propicio, Juan Luis buscó continuar sus estudios de antropología en otras latitudes. En 1975 llegó a México, donde cursó la maestría en antropología en la Universidad Iberoamericana. Ahí tuvo como profesores a varios de los mejores antropólogos mexicanos de aquella época: Gonzalo Aguirre Beltrán, Guillermo Bonfil, Ángel Palerm, Rodolfo Stavenhagen y Arturo Warman. En México se reforzó su convicción de que el trabajo de campo era uno de los ejes centrales de la práctica antropológica:

Y, desde luego, una de las cosas que más nos enseñó Ángel fue la ineludible tarea para el antropólogo del trabajo de campo. Aún cuando era un hombre de edad avanzada, seguía yendo a hacer trabajo de campo con sus estudiantes. Recuerdo que cuando hablabas con él de tus investigaciones, lo primero que te preguntaba era dónde están los datos

Charles Louis Joseph Vandame nació en 1928. Fue superior regional de los jesuitas de Chad entre 1968 y 1973, y arzobispo de N'Djamena de 1982 a 2003. 
de campo, qué vio en el campo. Porque él estaba al tanto de todo lo que hacíamos ahí en el CIS-INAH, de todos los proyectos. Yo, en esa época estaba haciendo trabajo de campo con los mineros de Cananea y él me preguntaba insistentemente acerca de esa zona que yo creo que conocía poco. Yo tengo que agradecerle mucho esa actitud que él me enseñó ante el trabajo de campo sistemático, algo que en otras escuelas de esa época no se defendía tanto (entrevista con Juan Luis Sariego, realizada por Luis Felipe Castro Oviedo, 24 de febrero de 2006). [Las cursivas son mías.]

Hay muchos antropólogos apasionados por el trabajo de campo, pero lo que distinguía a Juan Luis Sariego era que lo realizaba de manera organizada y rigurosa, con un sólido bagaje teórico y amplios recursos metodológicos. No se trataba sólo de convivir con los otros o de reunir información sin ton ni son, sino de un esfuerzo constante para teorizar a partir de la experiencia etnográfica y enriquecer los conceptos mediante el diálogo con los sujetos de estudio. Iba al campo con el espíritu abierto a nuevos descubrimientos, pero también con un proyecto intelectual, ya fuese teórico o aplicado: escribir una gramática nar, analizar el proceso de proletarización de los mineros de Pachuca y Real del Monte, problematizar e historizar el concepto de enclave (Sariego, 1988), realizar un inventario de los impactos del terremoto de 1985 en el centro histórico de la ciudad de México, estudiar la evolución de las políticas del Estado hacia la minería (Sariego et al.,

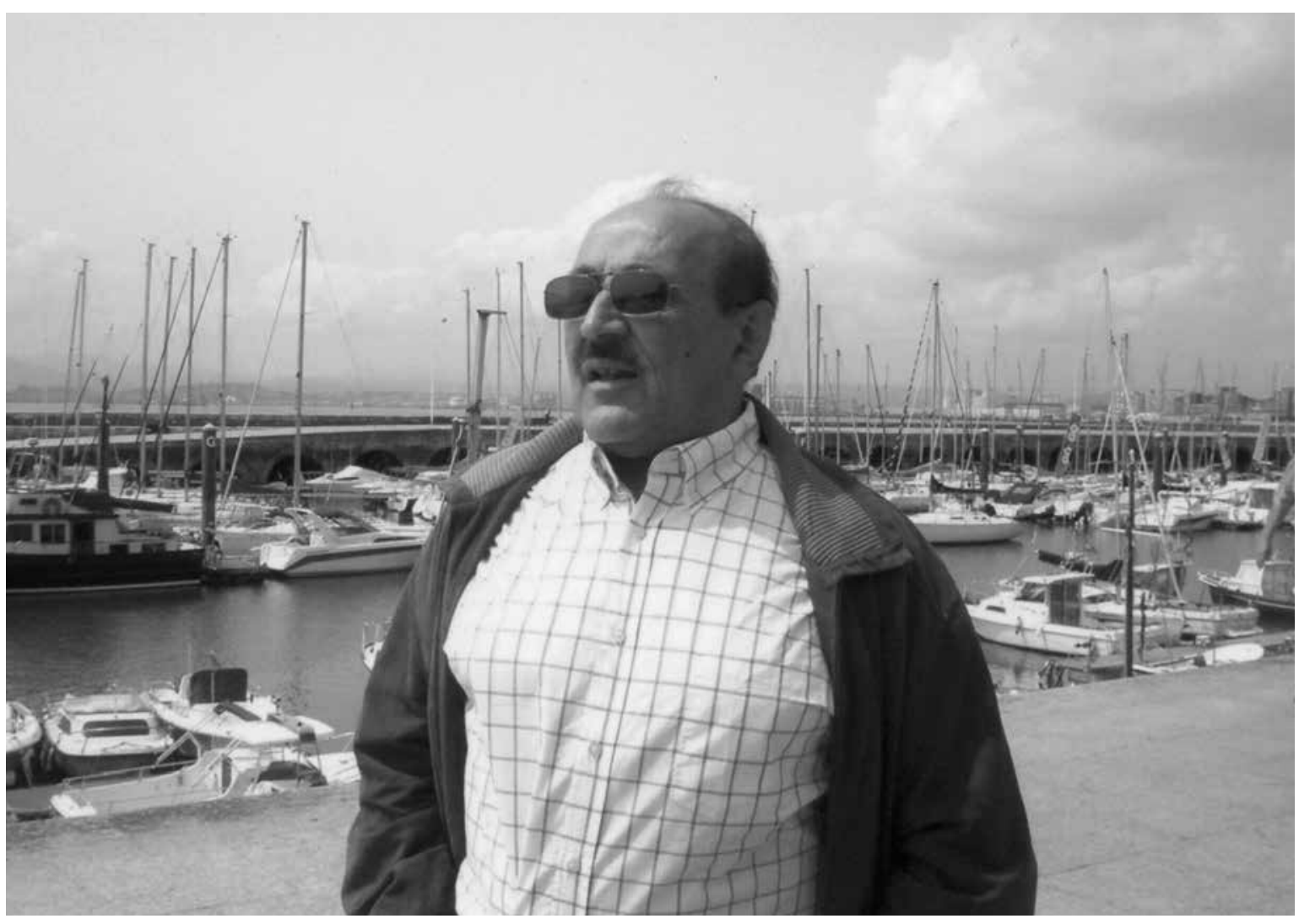

- Juan Luis Sariego de vacaciones en Santander, España, 1999. Paseo por el llamado "puerto chico", en el que se guardan los barcos de vela deportivos. 
1988), crear un programa de formación de antropólogos en el norte de México (Pérez et al., 2014), rescatar el archivo municipal de Uruachi, analizar la práctica indigenista y discutir los modelos de desarrollo en la Sierra Tarahumara (Sariego, 2003), por mencionar algunos de los proyectos de investigación antropológica en los que participó a lo largo de más de 40 años. Cuando falleció, en marzo de 2015, una de las coronas de flores que llevaron sus alumnos de la Escuela de Antropología e Historia del Norte de México (EAHNM) al funeral realizado en la ciudad de Chihuahua tenía la leyenda "Prometemos dejar de papalotear". Juan Luis insistía en la importancia de hacer trabajo de campo, pero de manera sistemática, sin papalotear.

\section{El hombre con quien aprendí el oficio}

Juan Luis Sariego hizo varias aportaciones sustantivas a la antropología mexicana. Un balance de todas ellas requeriría un texto más extenso, escrito por especialistas en cada tema. Baste recordar que, además de contribuir a la formación del campo de estudios sobre antropología del trabajo y cultura obrera, fue uno de los más profundos conocedores de la minería en México y sus investigaciones sobre la Tarahumara son una referencia obligada para el estudio del indigenismo realmente existente, no sólo el de los libros, sino el que se desarrolló en la práctica, en las poblaciones indígenas. Fue un promotor de la antropología aplicada con soporte académico, impulsor de la antropología del norte de México y constructor de instituciones. Contribuyó a la creación del CIS-INAH, de la maestría en antropología social de la ENAH y en particular a la creación y consolidación de la ENAH Chihuahua, hoy EAHNM. Creo que sus numerosos aportes se comprenden mejor si se tiene en cuenta al ser humano que los produjo y la manera en que Sariego concebía y practicaba la antropología.

Aprendí el oficio de antropólogo al lado de un gran maestro. Juan Luis Sariego nunca se puso a darme lecciones ni esperaba que me convirtiera en su discípulo, sino que me invitó a hacer trabajo de campo en condiciones de igualdad, con un grupo de colegas. A la manera en que me introdujo en el oficio se le podrían aplicar muchos viejos proverbios: "Un profesor enseña, con un maestro se aprende", "No dar pescados, sino enseñar a pescar", "Lanzarse a la alberca es la única manera de aprender a nadar". Yo preferiría recordar un proverbio de África, de la región en la que Juan Luis se forjó como antropólogo: "La mano que da siempre está por arriba de la que recibe”. Este dicho alude a las relaciones verticales y asimétricas que se establecen entre quien brinda ayuda y quien la recibe, algo que ocurre también en el campo académico. Él no cometió ese error. Más que ayudar a los alumnos, creaba condiciones adecuadas para que aprendieran. Pienso que Sariego fue un gran maestro porque no buscaba convertirse en un gurú rodeado de seguidores. Fue un antropólogo autodidacta, que invitaba a hacer trabajo de campo sistemático codo con codo, que concebía la antropología como un oficio que aspira a la igualdad en la diferencia, en el que se dialoga con los otros para comprender la diversidad cultural, en el que uno establece relaciones de enriquecimiento mutuo con los colegas y con las personas con quienes realiza sus investigaciones. Tuve la fortuna de aprender el oficio de antropólogo cerca de Juan Luis Sariego durante muchos años. Todo comenzó un domingo de junio de 1979. D 


\section{Bibliografía}

Molina, Daniel, 1978, La caravana del hambre, Ediciones el Caballito, México.

Pérez, Lourdes, Víctor Quintana, Luis Reygadas, Juan Luis Sariego, Margarita Urías y Augusto Urteaga, 2014, “Programa de formación en antropología del norte de México. Estudio diagnóstico de factibilidad y propuesta”, en Rodolfo Coronado (coord.), Vigésimo aniversario ENAH Chihuahua, Instituto Nacional de Antropología e Historia, México, pp. 19-93.

Reygadas, Luis, 1983, La lucha de los trabajadores de Nueva Rosita, tesis de licenciatura en antropología social, Escuela Nacional de Antropología e Historia, México.

- 1988, Proceso de trabajo y acción obrera. Historia sindical de los mineros de Nueva Rosita, 1929-1979, Instituto Nacional de Antropología Historia-Escuela Nacional de Antropología e Historia, México.

Juan Luis Sariego, 1973, Recueil de textes nar (Tchad), Groupe de la Mission Catholique, Sarh.

__ 1978, Los mineros de la Real del Monte. Características de un proceso de proletarización, Centro de Investigaciones Superiores del Instituto Nacional de Antropología e Historia-Cuadernos de la Casa Chata, México.

—_, 1988, Enclaves y minerales en el norte de México. Historia social de los mineros de Cananea y Nueva Rosita. 1900-1970, Centro de Investigaciones y Estudios Superiores en Antropología Social, México.

—_, 2003, El indigenismo en la Tarahumara. Identidad, comunidad, relaciones interétnicas y desarrollo en la Sierra de Chihuahua, Instituto Nacional Indigenista/Instituto Nacional de Antropología e Historia, México.

Juan Luis Sariego, Luis Reygadas, Miguel Ángel Gómez y Javier Farrera, 1988, El Estado y la minería mexicana. Política, trabajo y sociedad durante el siglo xx, Fondo de Cultura Económica, México.

Thompson, Edward, 1977, La formación histórica de la clase obrera: Inglaterra, 1780-1832, Laia, Barcelona.

Zapata, Francisco, 1977, “Enclaves y sistemas de relaciones industriales en América Latina”, Revista Mexicana de Sociología, vol. 39, núm. 2. pp. 719-731.

\section{Entrevistas}

Juan Luis Sariego, por Luis Felipe Castro Oviedo, 24 de febrero de 2006. 